\title{
Evaluation of the potential of the marine sponges of the Zanzibar Island to yield antimalarial and antimicrobial active compounds
}

\author{
S.A. SAID ${ }^{1}$, M.J.MOSHI2 ${ }^{*}$, R.S.O. NONDO², P.J. MASIMBA², E. INNOCENT² \\ and A.N. GUANTAI \\ ${ }^{1}$ Institute of Marine Sciences, P.O. Box 668, Zanzibar, Tanzania \\ 2 Institute of Traditional Medicine, Muhimbili University of Health and Allied Sciences, \\ P.O. Box 65001, Dar es Salaam, Tanzania \\ ${ }^{3}$ School of Pharmacy, College of Health Sciences, University of Nairobi, P. O. Box $19676-$ KNH, Nairobi, \\ Kenya
}

\begin{abstract}
Emergence of new and re-emergence of old infections continue to elude prospects of reducing morbidity and mortality caused by microbial infections. Trends of resistance to currently in use antimicrobials and antimalarials threaten to increase mortality caused by these infections. This study explores the potential of marine invertebrates as a source for new antimicrobials and antimalarials. The lactate dehydrogenase method was used to assay marine sponges for activity against Plasmodium falciparum, while the disc diffusion method was used to assay the extracts for antibacterial and antifungal activity. Extracts of some marine sponges from the Zanzibar Island exhibited both antiplasmodial and antimicrobial activities. Among the 55 marine sponge extracts that were tested $23(41.8 \%)$ inhibited Plasmodium falciparum W2 strain by more than $50 \%$ at both 250 and 50 $\mu \mathrm{g} / \mathrm{ml}$ concentrations. Moderate polar extracts were more active against Plasmodium falciparum W2 strain than polar and non-polar extracts. None of the 12 extracts that were tested on Plasmodium falciparum strain D6 exhibited inhibitory activity reaching 50\%. Among 18 marine sponge extracts that were tested for antimicrobial activity 12 (66.7\%) showed activity against one or more of the bacteria and fungi used ranging from weak to strong on an arbitrary criterion. The ethyl acetate extracts of Agelas mauritania and Oceanopia sp. exhibited high activity against the fungi Candida albicans and Cryptococcus neoformans. The best antibacterial profile was exhibited by ethyl acetate extracts of Aplysinopsis sp., Halichondrida sp. 1 and Oceanopia sp. In conclusion, these results support the need for intensified efforts to search for active antimalarial and antimicrobial compounds from the Zanzibar marine sponges.
\end{abstract}

Keywords: Antimalarial, antimicrobial activity; marine sponges, Zanzibar

\section{Introduction}

The optimism of the 1950s and 1960s of a world without infections is gradually being replaced by an era of pessimism characterized by widespread emergence of resistance among most of the major pathogens (Raghunath, 2008; Andersson \& Hughes, 2010). Microbial infections are still the major cause of mortality the world over (World Health Report, 2003). While the HIV/AIDS pandemic as well as emergent and re-emergent infections have brought a new dimension to antimicrobial chemotherapy (Nordberg et al., 2004), the steady discovery of novel antibiotics in the period 1940-1980 has not been sustained, and as a result the 1990s saw only one new antibiotic class, the oxazolidinones joining the approval list (Raghunath, 2008) .

* Correspondence: Prof. Mainen J. Moshi; E-mail: mmoshi@muhas.ac.tz 
Like bacterial infections, malaria chemotherapy is challenged by the emergence of drug resistant Plasmodium falciparum (Hyde et al., 2005). Widespread P. falciparum resistance to the most affordable agents, particularly chloroquine and sulfadoxine-pyrimethamine, undermine recent achievements made in malaria chemotherapy (Fegan et al., 2007; Hyde et al., 2005). Recently, artemisinin-based combination therapies (ACTs) were recommended by the World Health Organization (WHO) Roll Back Malaria group for treatment of uncomplicated malaria. ACTs are clinically effective, and may reduce malaria transmission rates and the potential for resistance development (Achuyt et al., 2007; Bousema et al., 2006; Sutherland et al., 2005). However, ACTs face great pharmacological challenges with regard to variable drug bioavailability, drug interactions, and the long half life of partner drugs that have implication in the development of resistant parasite mutants (German \& Aweeka, 2008; Kremsner \& Krishna, 2004; Talisuna et al., 2004). Recent reports suggest that there may already be signs of the emergence of invitro resistance to some artemisinins (Jambou et al., 2005; Uhlemann et al., 2005). Reports of rampant resistance to antimalarial and antimicrobial agents, is a loud trumpet calling for intensified efforts to search for new chemotherapeutic agents.

This study, led by promising results of drug bio-prospecting among marine invertebrates such as sponges, tunicates, bryozoans, and molluscs (Abdelmohsen et al., 2010; Orhan et al., 2010; Arai et al., 2009; Blunt et al., 2006; Haefner, 2003) seeks to further initiatives to discover antimicrobial and antimalarial drugs by evaluating the potential of some marine sponges collected off the Zanzibar coasts.

\section{Materials and methods}

\section{Collection of sponges}

Sponges were collected by snorkelling and SCUBA diving in diverse habitats (e.g. shallow and deep coral reefs, mangrove channels, sea grass habitats, lagoons, and estuaries) located on different parts of Zanzibar island shores. About 300-500 g pieces of sponges were collected and put into zip lock bags underwater to avoid mixing them. Prior to collection underwater photographs were taken for future identification. From each species a voucher sample was taken for taxonomical morphological identification. All samples were preserved at low temperature $\left(-20^{\circ} \mathrm{C}\right)$ in the laboratory.

\section{Extraction and creation of fraction libraries}

Freeze dried or wet samples were soaked twice in methanol and twice in a mixture of equal volumes of methanol/dichloromethane (1:1). Each soaking lasted $24 \mathrm{~h}$. After filtration solvents were evaporated under reduced pressure in a rotary evaporator and the extracts were combined. Aqueous combined extracts were then consecutively extracted with hexane, dichloromethane and n-butanol to obtain extracts with varying polarities.

\section{Screening for antiplasmodial activity}

Animalarial activity was assayed using plasmodium lactate dehydrogenase (pLDH) (Kaddouri et al., 2006). Chloroquine resistant Plasmodium falciparum strains W2 and D6 were used. Cultures of $P$. falciparum were maintained in vitro in human blood cells (O+ve) diluted to 5\% hematocrit with RPMI 1640 medium (10\% human O+ serum). Each extract was dissolved in DMSO and diluted with RPMI 1640 medium before testing. The concentration of DMSO in the test never exceeded $0.1 \%$. Portions (50 $\mu \mathrm{l}$ each) of diluted extract were 
dispensed into 96-well microtiter trays so as to yield final test concentrations of 250 and 50 $\mu \mathrm{g} \mathrm{ml}^{-1}$. All tests were performed in duplicate. To each well was added $50 \mu \mathrm{l}$ of human erythrocytes (O+ve, diluted to $5 \%$ hematocrit) with $1 \%$ parasitemia (dilutions to $1 \%$ parasitemia were made with uninfected washed erythrocytes). Two series of controls were performed, one with parasitized blood without extracts and another with uninfected erythrocytes without extracts. Incubation was carried out in a 5\% $\mathrm{O}_{2}-5 \% \mathrm{CO}_{2}-90 \% \mathrm{~N}_{2}$ gas phase for $72 \mathrm{~h}$ at $37^{\circ} \mathrm{C}$. After incubation $100 \mu \mathrm{l}$ of Malstat was added to each well. This was followed by addition of NTB/PES mixture (1:1). The plates were then de-bubbled, covered with aluminium foil and kept in a dark place for 1-2 h. Absorbance (optical density, OD) was measured at $260 \mathrm{~nm}$. Percent inhibition for the two concentrations was calculated.

\section{Antimicrobial test}

Antibacterial and antifungal activities were tested by the disc diffusion method (Singh et al., 2002). Bacteria and fungi used include: Staphylococcus aureus (NCTC 6571), Pseudomonas aeruginosa (NCTC 10662), Bacillus anthracis (NCTC 10073), Proteus mirabilis (NCTC 10975), Shigella dysenteriae (clinical isolate), and two fungi, Candida albicans (Strain HG 392), and Cryptococcus neoformans (clinical isolate) were used. Filter paper discs (Whatman no.1; $6 \mathrm{~mm}$ diameter) were impregnated with crude extracts $(5 \mathrm{mg} / \mathrm{disc})$ or standard drugs $(10 \mu \mathrm{g} / \mathrm{disc}$ gentamycin for bacteria, and $20 \mu \mathrm{g} /$ disc clotrimazole for fungi). The discs were placed on Mueller Hinton agar plates (for bacteria) and Saborauld's dextrose agar plates (for fungi) and incubated at $37^{\circ} \mathrm{C}$, for $24 \mathrm{~h}$. Each test was done in triplicate. Controls were blank discs impregnated with solvent. Inhibition zones were calculated as the difference between disc diameter $(6 \mathrm{~mm})$ and the diameters of inhibition (Hewitt \& Vincent, 1989). Activity index (AI) was calculated as the ratio of the mean inhibition zone (IZ) for the sample to that for standard drug (Singh et al., 2002).

\section{Results}

\section{Antimalarial tests}

The results of antimalarial activity presented in Table 1 show that 23 out of the 55 extracts tested (41.8\%) inhibited Plasmodium falciparum W2 strain by more than $50 \%$ at both 250 and $50 \mu \mathrm{g} / \mathrm{ml}$ concentrations. Seventeen out of these extracts displayed high potency at both low and high concentrations; these include extracts in Table 1 with entries 3, 10, 11, 13, 14, 15, 19, 23, and 27. Others are entries 30, 36, 39, 41, 44, 45, 47, and 52. The other extract entries exhibiting activity at $50 \%$ or higher are Table 1 entries number 12, 26, 33, 40 and 46 . None of the 12 extracts that were tested on Plasmodium falciparum strain D6 exhibited inhibitory activity reaching $50 \%$ (Table 2 ). 
Table 1: Invitro antiplasmodial activity of marine sponge extracts against Plasmodium falciparum Strain W2

\begin{tabular}{|c|c|c|c|c|c|}
\hline Entry & Sponge Code & Sponge ID & $\begin{array}{l}\text { Extract } \\
\text { type }\end{array}$ & $\begin{array}{l}\text { Mean \% Inhibition } \\
\text { at } 250 \mu \mathrm{g} / \mathrm{ml}\end{array}$ & $\begin{array}{l}\text { Mean \% Inhibition } \\
\text { at } 50 \mu \mathrm{g} / \mathrm{ml}\end{array}$ \\
\hline 1 & Z04A56 & Agelas mauritania & EA & 81.9 & 26.4 \\
\hline 2 & ZO4A 157 & Ancorinidae sp. & EA & 29.4 & 32.2 \\
\hline 3 & Z04A114 & Aplysinopsis sp. & EA & 95.9 & 88.1 \\
\hline 4 & Z04A94 & Axinellidae sp. & ME & 92.2 & 1.96 \\
\hline 5 & & Axinellidae sp. & DM & 50.5 & 2.0 \\
\hline 6 & Z04A65 & Callyspongia sp. & ME & 64.7 & 17.9 \\
\hline 7 & Z04A20 & Chalinidae sp. 1 & EA & 81.6 & 64.6 \\
\hline 8 & Z04A165 & Chalinidae sp. 2 & EA & 85.7 & 40.9 \\
\hline 9 & ZO4A 83 & Clathria sp. & BU & 37.3 & 36.4 \\
\hline 10 & Z04A149 & Cliona sp. 2 & EA & 88.8 & 83.3 \\
\hline 11 & Z04A158 & Cliona sp.1 & EA & 82.9 & 87.1 \\
\hline 12 & Z04A21 & Cribrochalina sp. & DM & 71.3 & 53.4 \\
\hline 13 & & Cribrochalina sp. & ME & 100 & 84.1 \\
\hline 14 & Z04A101 & Halichondrida sp.1 & EA & 94.8 & 87.3 \\
\hline 15 & Z04A111 & Halichondrida sp.2 & DM & 64.8 & 70.5 \\
\hline 16 & ZO4A 49 & Halichondrida sp.3 & EA & 31.4 & 33.6 \\
\hline 17 & Z04A130 & Halichondridae sp. 1 & $\mathrm{HX}$ & 70.4 & 8.2 \\
\hline 18 & Z04A151 & Halichondridae sp.2 & $\mathrm{HX}$ & 56.9 & 26.7 \\
\hline 19 & & Halichondridae sp. 2 & $\mathrm{DM}$ & 90.7 & 85.3 \\
\hline 20 & ZO4A 162 & Halisarca sp. & EA & 36.2 & 39.2 \\
\hline 21 & Z04A109 & Haplosclerina sp. & EA & 69.8 & 18.5 \\
\hline 22 & ZO4A 119 & Haplosclerina sp. 2 & EA & 40.6 & 33.3 \\
\hline 23 & Z04A50 & Haplosclerina sp.1 & $\mathrm{DM}$ & 88.1 & 61.2 \\
\hline 24 & & Haplosclerina sp.1 & HX & 0 & 0 \\
\hline 25 & ZO4A 36 & Haplosclerina sp.3 & BU & 34 & 27.6 \\
\hline 26 & Z04A150 & Hymeniacidon sp. & EA & 67.5 & 63.8 \\
\hline 27 & Z04A45 & Jaspis sp. & DM & 95.0 & 86.6 \\
\hline 28 & Z04A45 & Jaspis sp. & BU & 42.4 & 0 \\
\hline 29 & Z04A45 & Jaspis sp. & HX & 52.7 & 23.9 \\
\hline 30 & Z04A80 & Liosina sp. & $\mathrm{DM}$ & 72.4 & 70.9 \\
\hline 31 & & Liosina sp. & HX & 63.2 & 0 \\
\hline 32 & Z04A132 & Myxillina sp.1 & EA & 94.4 & 37.5 \\
\hline 33 & Z04A105 & Myxillina sp. 2 & HX & 78.9 & 50.8 \\
\hline 34 & Z04A67 & Niphatidae sp. 1 & DM & 52.4 & 6.4 \\
\hline 35 & ZO4A 133 & Niphatidae sp.2 & EA & 34.2 & 31.2 \\
\hline 36 & Z04A120 & Oceanopia sp. & EA & 96.7 & 91.2 \\
\hline 37 & Z04A192 & Petrosiidae sp. & EA & 25.4 & 0 \\
\hline 38 & Z04A74 & Phloeodictyidae sp. & EA & 59.2 & 34.2 \\
\hline 39 & Z04A24 & Pseudoceractina Arabica & ME & 80.6 & 80.2 \\
\hline 40 & & Pseudoceractina Arabica & DM & 61.6 & 56.4 \\
\hline 41 & Z04A156 & Pseudoceractina clavata & EA & 95.9 & 82.7 \\
\hline 42 & Z04A147 & Spirastrella sp. & $\mathrm{HX}$ & 59.9 & 9.5 \\
\hline 43 & Z04A26 & Spongidae & $\mathrm{ME}$ & 93.0 & 44.8 \\
\hline 44 & Z04A143 & Stylisa carteri & EA & 88.2 & 94.2 \\
\hline 45 & Z04A145 & Suberites $s p$. & EA & 94.4 & 78.9 \\
\hline 46 & Z04A155 & Tedania sp. 1 & $\mathrm{HX}$ & 65.7 & 54.4 \\
\hline 47 & Z04A152 & Tedania sp. 2 & EA & 91.9 & 94.4 \\
\hline 48 & Z04A17 & Tedaniidae sp. & EA & 63.1 & 35.1 \\
\hline 49 & Z04A07 & Tetillidae sp. & EA & 26.2 & 0 \\
\hline 50 & & Tetillidae sp. & $\mathrm{HX}$ & 29.7 & 22.4 \\
\hline 51 & & Tetillidae sp. & $\mathrm{DM}$ & 33.5 & 34.5 \\
\hline
\end{tabular}




\begin{tabular}{|l|l|l|l|l|l|}
\hline 52 & Z04A81 & Theonella swinhoei & EA & 97.3 & 96.3 \\
\hline 53 & ZO4A 95 & Thorectidae sp. & EA & 39.9 & 43.5 \\
\hline 54 & ZO4A 53 & Verongida $s p$. & BU & 42.6 & 40.9 \\
\hline 55 & & Verongida $s p$. & HX & 39.9 & 29.4 \\
\hline
\end{tabular}

Key: BU: n-butanol (n-BuOH) extract; DM: dichloromethane $\left(\mathrm{CH}_{2} \mathrm{Cl}_{2}\right)$ extract; EA: ethylacetate (EtOAc) extract; HX: n-hexane (n- $\left.\mathrm{C}_{6} \mathrm{H}_{14}\right)$ extract; ME: methanol (MeOH) extract

\section{Antimicrobial tests}

The results in Table 3 show that among 18 marine sponge extracts that were tested for antimicrobial activity $12(66.7 \%)$ showed activity against one or more of the organisms used ranging from weak to strong on the following arbitrary criterion: $0-5 \mathrm{~mm}$ of inhibition = very weak activity; $6-10 \mathrm{~mm}$ of inhibition = weak activity; $11-20 \mathrm{~mm}$ of inhibition = good activity; $>20 \mathrm{~mm}$ inhibition $=$ strong activity. Six extracts exhibited weak antibacterial activity against one or more organism. Two extracts exhibited good activity against Candida albicans; these are ethyl acetate extracts of Halichondrida sp. 1 and Oceanopia sp. The ethyl acetate extracts of Agelas mauritania, Hymeneciadon sp., Oceanopia sp., and hexane extract of Tedania sp. 1 exhibited good to strong activity against Cryptococcus neoformans (Table 3). Aplysinopsis sp. ethyl acetate extract showed good activity against both Bacillus anthracis and Staphylococcus aureus; Halichondria sp. 1 ethyl acetate extract was active against Bacillus anthracis (strong activity), Proteus mirabilis (good activity), and Staphylococcus aureus (good activity). The ethyl acetate extract of Oceanopia sp. also exhibited good antibacterial activity against Shigella dysentriae, Bacillus anthracis, Proteus mirabilis, and Staphylococcus aureus.

Table 2: Results of in vitro antiplasmodial activity testing of sponge extracts against Plasmodium falciparum Strain D6

\begin{tabular}{|c|c|c|c|c|}
\hline Entry & Sponge ID & Extract type & $\begin{array}{l}\text { Mean \% } \\
\text { Inhibition at } \\
250 \mu \mathrm{g} / \mathrm{ml}\end{array}$ & $\begin{array}{l}\text { Mean } \\
\text { Inhibition } \\
50 \mu \mathrm{g} / \mathrm{ml}\end{array}$ \\
\hline 1 & Chalinidae sp.2 & EA & 26.7 & 9.3 \\
\hline 2 & Clathria sp. & DM & 23.6 & 20.8 \\
\hline 3 & Clathria sp. & $\mathrm{HX}$ & 35.1 & 28.6 \\
\hline 4 & Haplosclerida sp. & EA & 23.1 & 22.5 \\
\hline 5 & Haplosclerina sp.3 & DM & 22.9 & 26.3 \\
\hline 6 & Haplosclerina sp.3 & $\mathrm{HX}$ & 28.7 & 25.9 \\
\hline 7 & Haplosclerina sp.4 & $\mathrm{HX}$ & 33 & 17.4 \\
\hline 8 & Haplosclerina sp.4 & $\mathrm{DM}$ & 29.9 & 11.5 \\
\hline 9 & Haplosclerina sp.5 & EA & 13.7 & 11.5 \\
\hline 10 & Spirastrella sp. & $\mathrm{BU}$ & 9.9 & 11.7 \\
\hline 11 & Tedaniidae sp. & EA & 28.3 & 22.8 \\
\hline 12 & Verongida sp. & DM & 29.0 & 25.9 \\
\hline
\end{tabular}

Key: BU: n-butanol (n-BuOH) extract; DM: dichloromethane $\left(\mathrm{CH}_{2} \mathrm{Cl}_{2}\right)$ extract; EA: ethylacetate (EtOAc) extract; HX: n-hexane (n- $\left.\mathrm{C}_{6} \mathrm{H}_{14}\right)$ extract; ME: methanol $(\mathrm{MeOH})$ extract

Among the 18 extracts tested 6 (33.3\%) had neither antibacterial nor antifungal activity (Table 3). These include ethyl acetate extracts of Cliona sp. 1 and sp. 2, ethyl acetate extract of Halichondrida sp. 4 and sp. 1, hexane extract of Myxillina sp. 2, and ethyl acetate extracts of Pseudoceratina clavata and Suberites sp. 1. 
The results of the inhibition of bacterial and fungal growth by sponges extracts are summarised in Table 3. Results are reported as inhibition zones (IZ; mm) with the corresponding activity index (AI). IZ are presented as mean $\pm \mathrm{SD}(\mathrm{n}=3)$. Inhibition zones exclude the disc diameter $(6 \mathrm{~mm}) ; \mathrm{AI}=\mathrm{IZ}$ of test sample divided by $\mathrm{IZ}$ of standard drug. 
Table 3: Inhibition of bacterial and fungal growth by sponges extracts $(5 \mathrm{mg} / \mathrm{disc})$

\begin{tabular}{|c|c|c|c|c|c|c|c|c|c|c|c|c|c|c|c|}
\hline \multirow[t]{4}{*}{ Sponge ID } & \multirow{2}{*}{$\begin{array}{c}\text { Extracts } \\
\text { /drugs }\end{array}$} & \multicolumn{2}{|c|}{ S.dysentriae } & \multicolumn{2}{|c|}{ B.anthracis } & \multicolumn{2}{|c|}{ P.mirabilis } & \multicolumn{2}{|c|}{ P.aeruginosa } & \multicolumn{2}{|c|}{ S.aureus } & \multicolumn{2}{|c|}{ C.albicans } & \multicolumn{2}{|c|}{ C.neoformans } \\
\hline & & $\mathrm{IZ}$ & $\mathrm{AI}$ & $\mathrm{IZ}$ & $\mathrm{AI}$ & $\mathrm{IZ}$ & $\mathrm{AI}$ & $\mathrm{IZ}$ & $\mathrm{AI}$ & $\mathrm{IZ}$ & $\mathrm{AI}$ & $\mathrm{IZ}$ & $\mathrm{AI}$ & $\mathrm{IZ}$ & $\mathrm{AI}$ \\
\hline & Gent & $21.0 \pm 0.5$ & 1.0 & $23.0 \pm 0.7$ & 1.0 & $23.0 \pm 0.5$ & 1.0 & $18.0 \pm 0.3$ & 1.00 & $25.0 \pm 0.7$ & 1.00 & NT & & NT & 0 \\
\hline & Clot & NT & & NT & & NT & & NT & & NT & & $20 \pm 0.5$ & 1.00 & $18 \pm 0.5$ & 1.0 \\
\hline Agelas Mauritania & EA & 0 & 0 & 0 & 0 & 0 & 0 & 0 & 0 & 0 & 0 & 0 & 0 & $20.0 \pm 0.3$ & 1.1 \\
\hline Aplysinopsis sp. & EA & 0 & 0 & $15.3 \pm 0.2$ & 0.7 & $6.0 \pm 0.1$ & 0.3 & 0 & 0 & $13.0 \pm 0.3$ & 0.5 & 0 & 0 & 0 & 0 \\
\hline Axinellidae sp. & ME & 0 & 0 & 0 & 0 & 0 & 0 & 0 & 0 & $7.6 \pm 0.2$ & 0.3 & 0 & 0 & 0 & 0 \\
\hline Cliona sp.1 & EA & 0 & 0 & 0 & 0 & 0 & 0 & 0 & 0 & 0 & 0 & 0 & 0 & 0 & 0 \\
\hline Cliona sp.2. & EA & 0 & 0 & 0 & 0 & 0 & 0 & 0 & 0 & 0 & 0 & 0 & 0 & 0 & 0 \\
\hline Halichondrida sp.1 & EA & $7.0 \pm 0.2$ & 0.3 & $22.3 \pm 0.1$ & 1.0 & $18.3 \pm 0.1$ & 0.8 & $7.0 \pm 0.5$ & 0.39 & $17.3 \pm 0.7$ & 0.7 & $15.3 \pm 0.4$ & 0.8 & 0 & 0 \\
\hline Halichondrida sp.4 & EA & 0 & 0 & 0 & 0 & 0 & 0 & 0 & 0 & 0 & 0 & 0 & 0 & 0 & 0 \\
\hline Halichondridae sp.2 & $\mathrm{DM}$ & 0 & 0 & $7.0 \pm 0.2$ & 0.3 & $9.0 \pm 0.5$ & 0.4 & 0 & 0 & $6.0 \pm 0.5$ & 0.2 & 0 & 0 & 0 & 0 \\
\hline Haplosclerina sp.1 & $\mathrm{HX}$ & 0 & 0 & 0 & 0 & 0 & 0 & 0 & 0 & 0 & 0 & 0 & 0 & 0 & 0 \\
\hline Hymeneciadon sp. & EA & $8.6 \pm 0.6$ & 0.4 & $9.6 \pm 0.5$ & 0.4 & 0 & 0 & 0 & 0 & 0 & 0 & 0 & 0 & $19.6 \pm 0.4$ & 1.1 \\
\hline Jaspis sp. & $\mathrm{BU}$ & 0 & 0 & $8.3 \pm 0.3$ & 0.4 & $10.3 \pm 0.5$ & 0.4 & 0 & 0 & $10.0 \pm 0.5$ & 0.4 & 0 & 0 & 0 & 0 \\
\hline Jaspis sp. & $\mathrm{DM}$ & 0 & 0 & $6.0 \pm 0.3$ & 0.3 & 0 & 0 & 0 & 0 & 0 & 0 & 0 & 0 & 0 & 0 \\
\hline Myxillina sp.2 & $\mathrm{HX}$ & 0 & 0 & 0 & 0 & 0 & 0 & 0 & 0 & 0 & 0 & 0 & 0 & 0 & 0 \\
\hline Oceanopia sp. & EA & $15.0 \pm 0.3$ & 0.7 & $17.0 \pm 0.4$ & 0.7 & $14.0 \pm 0.4$ & 0.6 & 0 & 0 & $10.3 \pm 0.5$ & 0.4 & $16.6 \pm 0.2$ & 0.8 & $20.3 \pm 0.6$ & 1.1 \\
\hline $\begin{array}{l}\text { Pseudoceractina } \\
\text { clavata }\end{array}$ & EA & 0 & 0 & 0 & 0 & 0 & 0 & 0 & 0 & 0 & 0 & 0 & 0 & 0 & 0 \\
\hline Stylisa carteri & EA & 0 & 0 & $8.3 \pm 0.2$ & 0.4 & $6.0 \pm 0.5$ & 0.3 & $6.3 \pm 0.4$ & 0.35 & $9.0 \pm 0.3$ & 0.4 & $6.0 \pm 0.3$ & 0.3 & 0 & 0 \\
\hline Suberites sp. & EA & 0 & 0 & 0 & 0 & 0 & 0 & 0 & 0 & 0 & 0 & 0 & 0 & 0 & 0 \\
\hline Tedania sp.1 & $\mathrm{HX}$ & 0 & 0 & $6.3 \pm 0.3$ & 0.3 & 0 & 0 & 0 & 0 & 0 & 0 & 0 & 0 & $16.6 \pm 0.3$ & 0.9 \\
\hline
\end{tabular}

oromethane $\left(\mathrm{CH}_{2} \mathrm{Cl}_{2}\right)$ extract; EA: ethylacetate (EtOAc) extract; HX: n-hexane (n-C6 $\left.\mathrm{H}_{14}\right)$ extract; ME: methanol (MeOH) extract; Sdys: S. dysenteriae; Banth: Bacillus anthracis; Paer:

Pseudomonus aeruginosa; Pmir P. mirabilis; Saur: Staphylococcus aureus; Calb: Candida albicans; Cneof: Candida neoformans; Gent: gentamycin; Clot: clotrimazole. 


\section{Discussion}

In general the moderate polar extracts (ethyl acetate and dichloromethane) were more active than the polar (methanol and butanol) and non-polar (hexane) extracts. All tested samples were inactive against Plasmodium falciparum D6 strains as shown in Table 2. The observed antiplasmodial activity in the marine invertebrate extracts is not unique as there are similar previous reports of isolation of antimalarial compounds from marine sources (Orhan et al., 2010; Lazaro et al., 2002; El-Sayed et al., 2001). Invitro antiplasmodial activity of heptyl prodigiosin, isolated from a marine tunicate obtained from Philippines against $P$. falciparum 3D7 strain was reported to be similar to that of chloroquine [ $\mathrm{IC}_{50}=0.07$ vs. $0.015 \mu \mathrm{M}$, respectively] (Lazaro et al., 2002). A detailed review on antimalarial compounds isolated from marine organisms is given by Mayer \& Hamann (2005).

Despite the unfortunate situation that there were no enough extracts to determine the $\mathrm{IC}_{50}$ values for the active extracts, this study has been the first to report on antimalarial activity of marine invertebrates from the Zanzibar Islands. This should create more interest to build on the results and eventually isolate active antiplasmodial compounds from Tanzanian marine sponges.

More than $70 \%$ of the species tested inhibited the growth of one or more of the micro-organisms tested. This wide distribution of antimicrobial activity is similar to that found in species from tropical and temperate marine waters (Rinehart et al., 1981). It is interesting to note that the ethyl acetate extracts of Hymeniacidon sp, Agelas mauritania, Halichondrida sp.1and Oceanopia sp.and hexane extract of Tedania sp. 1 possess very potent activities against the fungi Candida albicans and C.neoformans. Activities exhibited by $5 \mathrm{mg} / \mathrm{ml}$ extracts of these sponges are comparable to that of the azole antifungal clotrimazole. The ethyl acetate extract of Agelas mauritania showed selective activity against C.neoformans. It will thus be worthwhile to isolate the active antifungal compound/s from this extract. The antibacterial activities of Aplysinopsis sp., Halichondrida sp. 1, and Oceanopia sp. ethyl acetate extracts are also interesting enough, thus needing further work to isolate the active compounds. These extracts exhibited activity against both Gram positive and Gram negative bacteria. Antimicrobial properties displayed by the sponges tested in this study are comparable to results obtained on soft corals collected from the same coasts (Nyanda, 1992).

In conclusion, the results indicate potential to isolate active antiplasmodial, antibacterial and antifungal compounds from Tanzanian marine invertebrates.

\section{Acknowledgements}

We would like to thank all the technical staff of the Institute of Marine Sciences in Zanzibar for the great work of collecting the sponges. We also thank all the staff of the Department of Biological and Pre-clinical Studies at ITM for supportive work. This work was supported by a research grant from $\mathrm{WHO} / \mathrm{TDR}$.

\section{References}

Abdelmohsen, U.R., Pimentel-Elardo, S.M., Hanora, A., Radwan, M., Abou-El-Ela, S.H., Ahmed, S. \& Hentschel, U. (2010) Isolation, Phylogenetic Analysis and Anti-infective Activity Screening of Marine Sponge-Associated Actinomycetes. Marine Drugs 8, 399412. 
Andersson, D.I. \& Hughes, D. (2010) Antibiotic resistance and its cost: is it possible to reverse resistance? Nature Reviews/Microbiology 8:260-271.

Arai, M., Ishida, S., Setiawan, A. \& Motomasa Kobayashi, M. (2009) Haliclonacyclamines, tetracyclic alkylpiperidine alkaloids, as anti-dormant mycobacterial substances from a marine sponge of Haliclona sp. Chemical and Pharmacetical Bulletin 57, 1136-1138.

Bhattarai, A., Ali, A.S., Kachur, P., Mårtensson, A., Abbas, A.K., Khatib, R., Al-Mafazy, A., Ramsan, M., Rotllant, G., Gerstenmaier, J.F., Molteni, F., Abdulla, S., Montgomery, S.M., Kaneko, A. \& Björkman, A. (2007) Impact of artemisinin-based combination therapy and insecticide-treated nets on malaria burden in Zanzibar. PLoS Medicine 4:e309.

Blunt, J.W., Copp, B.R, Munro, M.H.G., Northcote, P.T. \& Prinsep, M.R. (2006) Marine Natural Products. Natural Products Reports 23, 26-78.

Bousema, J.T., Schneider, P., Gouagna, L.C., Drakeley, C., Tostmann, A., Houben, R., Githure, J.I., Ord, R., Sutherland, C.J., Omar, S.A. \& Sauerwein, R.W. (2006) Moderate effect of artemisinin-based combination therapy on transmission of Plasmodium falciparum. Journal of Infectious Diseases 193:1151-9.

El-Sayed, K.A. Kelly, M., Kara, U.A., Ang, K.K., Katsuyama, I., Dunbar, D.C., Khan, A.A. \& Hamann M.T. (2001) New manzamine alkaloids with potent activity against infectious diseases. Journal of the American Chemical Society 123, $1804-1808$.

Fegan, G.W., Noor, A.M., Akhwale, W.S., Cousens, S. \& Snow, R.W. (2007) Effect of expanded insecticide-treated bednet coverage on child survival in rural Kenya: a longitudinal study. Lancet 370 (9592), 1035-9

German, P.I. \& Aweeka, F.T. (2008) Clinical pharmacology of artemisinin-based combination therapies. Clinical Pharmacokinetics 47, 91-102.

Haefner, B. (2003) Drugs from the deep: marine natural products as drug candidates. Drug Discovery Today 8, 536-544.

Hewitt, W. \& Vincent, S. (1989) In Theory and application of Microbial Assay. Academic Press, San Diego, p. 39.

Hyde, J.E. (2005) Drug-resistant malaria. Trends in Parasitology 21, 494-8

Jambou, R., Legrand, E., Niang, M., Khim, N., Lim, P., Volney, B., Ekala, M.T., Bouchier, C., Esterre, P., Fandeur, T. \& Mercereau-Puijalon, O. (2005) Resistance of Plasmodium falciparum field isolates to in-vitro artemether and point mutations of the SERCA-type PfATPase6. Lancet 366, 1960-1963.

Kaddouri, H., Nakache,S., Houzé, S., Mentré, F. \& Le Bras, J. (2006) Assessment of the drug susceptibility of Plasmodium falciparum clinical isolates from Africa by using a plasmodium lactate dehydrogenase immunodetection assay and an inhibitory maximum effect model for precise measurement of the 50-percent inhibitory concentration. Antimicrobial Agents and Chemotherapy 50, 3343-3349.

Kremsner, P.G. \& Krishna, S. (2005) Antimalarial combinations. Lancet 364, 285-294.

Lazaro, J.E., Nitcheu, J., Predicala, R.Z., Mangalindan, G.C., Nesslany, F., Marzin, D., Concepcion, G.P. \& Diquet, B. (2002) Haptyl prodigiosin, a bacterial metabolite, is antimalarial in vivo and non-mutagenic in vitro. Journal of Nature Toxins 1, 367-377.

Mayer A.M. \& Hamann, M.T. (2005) Marine pharmacology in 2001-2002; Marine compounds with anthelmintic, antibacterial, anticoagulant, antidiabetic, antifungal, anti-inflammatory, antimalarial, antiplatelet, antiprotozoal, antituberculosis, and antiviral activities; affecting the cardiovascular, immune and nervous systems and 
other miscellaneous mechanisms of action. Comparative Biochemistry and Physiology, Part C 140, 265- 286.

Nordberg, P., Monet, D.L. \& Cars, O. (2004) Background document for WHO project: Priority medicines for Europe and the World "A Public Health approach to Innovation". Accessible http://mednet3.who.int/priorityneeds/

Nyanda, J.N. (1992) Screening for antimicrobial compounds from some Tanzanian soft corals M.Sc. Dissertation, University of Dar Es Salaam, Dar Es Salaam, Tanzania.

Orhan, I., Şener, B., Kaiser, M., Brun, R. \& Tasdemir, D. (2010) Inhibitory activity of marine sponge-derived natural products against parasitic protozoa. Marine Drugs 8, 47-58.

Raghunath, D. (2008) Emerging antibiotic resistance in bacteria with special reference to India. Journal of Biosciences 33, 593-603.

Rinehart, K.L., Jr., Shaw, P.D., Shield, L.S., Gloer, J.B., Harbour, G.C., Koker, H.E.S., Samain, D., Schwartz, R.E., Tymiak, A.A., Weller, D.L., Carter, G.T., Munroe, H.H.G., Hughes, R.J. Jr., Renis, R.E., Swyenberg, E.B., Stringfellow, D.A., Vavra, J.J., Coats, J.H., Zurenko, G.E., Kuentzel, S.L., Li, L.H., Bakus, G.J., Brusca, R.C., Craft, L.L., Young, D.N. \& Connor, J.L. (1981) Marine natural products as sources of antiviral, antimicrobial, and antineoplastic agents. Pure and Applied Chemistry, 53, 795-817.

Singh, B., Sahu, P.M. \& Sharma, M.K., (2002) Anti-inflammatory and Antimicrobial activities of triterpenoids from Strobilanthes callosus Nees. Phytomedicine 9, 355-359.

Sisowath, C., Ferreira, P.E., Bustamante, L.Y., Dahlström, S., Mårtensson, A., Björkman, A., Krishna, S. \& Gil, J.P. (2007) The role of pfmdr1 in Plasmodium falciparum tolerance to artemether-lumefantrine in Africa. Tropical Medicine and International Health 12, 736742 .

Sutherland, C.J., Ord, R., Dunyo, S., Jawara, M., Drakeley, C.J., Alexander, N., Coleman, Pinder, M., Walraven, G. \& Targett, G.A. (2005) Reduction of malaria transmission to Anopheles mosquitoes with a six-dose regimen of co-artemether. PLoS Medicine 2:e92

Talisuna, A.O., Bloland, P. \& D'Alessandro, U. (2004) History, dynamics, and public health importance of malaria parasite resistance. Clinical Microbiology Reviews 17, 235-254.

Uhlemann, A.C., Cameron, A., Eckstein-Ludwig, U., Fischbarg, J., Iserovich, P., Zuniga, F.A., East, M., Lee, A., Brady, L., Haynes, R.K. \& Krishna, S. (2005). A single amino acid residue can determine the sensitivity of SERCAs to artemisinins. Nature Structural $\mathcal{E}$ Molelular Biology 12, 628-629.

World Health Report 2003 Shaping the future (Geneva: World Health Organization) (URL: http://www.who.int/whr/2003/en/) 